\title{
ARTICLE
}

Received 5 Aug 2015 | Accepted 11 Dec 2015 | Published 22 Jan 2016

DOI: $10.1038 /$ ncomms10449 OPEN

\section{Large deglacial shifts of the Pacific Intertropical Convergence Zone}

\author{
A.W. Jacobel ${ }^{1,2}$, J.F. McManus ${ }^{1,2}$, R.F. Anderson ${ }^{1,2} \&$ G. Winckler ${ }^{1,2}$
}

The position of the Intertropical Convergence Zone (ITCZ) is sensitive to changes in the balance of heat between the hemispheres which has fundamental implications for tropical hydrology and atmospheric circulation. Although the ITCZ is thought to experience the largest shifts in position during deglacial stadial events, the magnitude of shifts has proven difficult to reconstruct, in part because of a paucity of high-resolution records, particularly those including spatial components. Here we track the position of the ITCZ from 150 to $110 \mathrm{ka}$ at three sites in the central equatorial Pacific at sub-millennial time resolution. Our results provide evidence of large, abrupt changes in tropical climate during the penultimate deglaciation, coincident with North Atlantic Heinrich Stadial 11 ( 136-129 ka). We identify this event both as a Northern Hemisphere increase in aeolian dust and as a shift in the mean position of the ITCZ a minimum of $4^{\circ}$ southwards at $160^{\circ} \mathrm{W}$.

\footnotetext{
${ }^{1}$ Department of Earth and Environmental Sciences, Columbia University, New York, New York 10027, USA. ${ }^{2}$ Lamont-Doherty Earth Observatory, Palisades, New York 10964, USA. Correspondence and requests for materials should be addressed to A.W.J. (email: jacobel@ldeo.columbia.edu).
} 
T he Intertropical Convergence Zone (ITCZ) is a band of vigorous atmospheric convection and precipitation that varies position seasonally in connection with the latitude of maximum local insolation and on longer timescales in response to changes in the thermal equator 1,2 . This sensitivity has been reproduced in model experiments $\mathrm{s}^{3,4}$ and is indicated by a variety of palaeoclimate reconstructions covering the Last Glacial Maximum, last deglaciation and Holocene $e^{5-7}$. Because the ITCZ monitors the hemispheric thermal balance, its past positions record the (a)symmetry of climate changes and can provide insight into the hemispheric origin of millennial and orbital climate events. As an active component of the global hydrological system, the ITCZ also propagates changes at high latitudes into the tropics by altering albedo, regional precipitation and wind fields ${ }^{8}$. Understanding the forcings and dynamics behind these atmospheric shifts is important for predicting future changes in the ITCZ/monsoon complex with significant implications for communities living in hydrologically sensitive environments ${ }^{9}$. On longer timescales, studies have suggested that the ITCZ may exert an influence on the positions of the Southern Hemisphere subtropical jet and westerly winds ${ }^{10,11}$, which it is hypothesized are an essential element of deglacial Southern Ocean upwelling ${ }^{12}$. Accounting for past changes in ITCZ position is thus critical to our understanding of global ocean-atmosphere dynamics, tropical hydrology and the ocean's role in regulating atmospheric $\mathrm{pCO}_{2}$.

As expected, given the role of ITCZ precipitation in scavenging particles from the atmosphere, previous work has found that Pacific Ocean core sites underlying the ITCZ display a latitudinal gradient in dust flux ${ }^{13}$ and provenance ${ }^{14,15}$. When the amount of suspended dust is the same, greater precipitation yields more dust to the underlying sediments and therefore relative dust flux can be used as a proxy for ITCZ position. Specifically, the edges of the ITCZ will have higher dust fluxes than sites within the ITCZ due to lower residual dust availability towards the interior of the ITCZ $^{13}$. However, it is essential to recognize that a site exhibiting a temporal maximum in dust flux does not necessarily mean that the ITCZ has moved over that site, since the amount of suspended dust is not always the same above all core sites. Because the ITCZ is a barrier to cross-hemispheric dust transport ${ }^{14,16}$, variations in ITCZ latitude can force substantial changes in the provenance and amount of dust above a site. This nuance requires that we use independent dust flux data, in this case from Antarctica ${ }^{17}$, to inform our interpretations. Combined with our latitudinal transect and attention to relative dust flux variations between core sites, this approach allows us to differentiate between changes in atmospheric dust abundance and shifts in ITCZ position.

The central equatorial Pacific's Line Islands are well positioned to be sensitive to changes in the ITCZ because at this longitude the precipitation structure is well defined, with little deflection due to continental effects. Our records are derived from a latitudinal transect of three sediment cores: ML1208-37BB (37BB) at $7.04^{\circ} \mathrm{N}, 161.63^{\circ} \mathrm{W}$ and $2,798 \mathrm{~m}$ water depth; ML1208-31BB (31BB) at $4.68^{\circ} \mathrm{N}, 160.05^{\circ} \mathrm{W}$ and $2,857 \mathrm{~m}$ depth; and ML1208-17PC (17PC) at $0.48^{\circ} \mathrm{N}, 156.45^{\circ} \mathrm{W}$ and $2,926 \mathrm{~m}$ depth (Fig. 1). Core 37BB is located near the local modern boreal summer maximum of the ITCZ $\left(\sim 7^{\circ} \mathrm{N}\right)$, and 17PC is south of the local boreal winter minimum of $\sim 5^{\circ} \mathrm{N}$ (ref. 18).

We present high-resolution records of dust flux from 150 to $110 \mathrm{ka}$ at three sites in the Line Islands to constrain the ITCZ position during the penultimate deglaciation (Termination II or TII). These records place latitudinal constraints on the millennialscale movement of the Pacific ITCZ over this time period. Our data reconstruct a large, abrupt change in tropical Pacific climate over TII, characterized by both an increase in atmospheric dust abundance and by a shift of the ITCZ of at least $4^{\circ}$ southwards.
This tropical event is coincident with Heinrich Stadial 11 (HS11). After TII, dust fluxes declined to interglacial levels and the ITCZ shifted northwards of its previous glacial position.

\section{Results}

Sedimentation rates. Sedimentation rates vary between cores and within cores with average rates for the interval studied $(110-150 \mathrm{ka})$ of $1.1,4.8$ and $3.0 \mathrm{~cm} \mathrm{ka}^{-1}$ for cores $37 \mathrm{BB}, 31 \mathrm{BB}$ and 17PC respectively. A higher level of confidence is placed on conclusions when the sedimentation rate is higher, notably for the deglacial interval key to our primary interpretations in this paper. Details on the development of the age models from which these sedimentation rates are derived may be found in Methods.

Dust flux data. Dust fluxes were reconstructed using ${ }^{230} \mathrm{Th}_{\mathrm{xs}, 0}$-normalized ${ }^{232} \mathrm{Th}$ fluxes (Supplementary Data 1) as described in Methods. Data for sites 37BB, 31BB and 17PC (Fig. 2b) show similar trends in time from Marine Isotope Stage (MIS) 6 through MIS5. During MIS6 (oldest part of record to $\sim 140 \mathrm{ka})$ all cores show high dust deposition $\left(>0.25 \mathrm{~g} \mathrm{~m}^{-2}\right.$ $\mathrm{yr}^{-1}$ ) relative to the interglacial. At the peak glacial (as marked by the maxima in oxygen isotope values; Fig. 2a) the northernmost core is the first to show a small increase in dust flux, followed by the two more southerly cores between $\sim 136$ and $135 \mathrm{ka}$. Deglacial dust flux maxima occur in cores $31 \mathrm{BB}$ and 17PC between $\sim 133.4$ and $134.5 \mathrm{ka}$, and after that values in all cores decline precipitously reaching a minimum $\left(0.1\right.$ to $\left.0.15 \mathrm{~g} \mathrm{~m}^{-2} \mathrm{yr}^{-1}\right)$ during the MIS5 interglacial. This interglacial dust flux value is $\sim 2.5$ times lower than glacial values. For the remainder of the records all three cores show gradually increasing dust fluxes.

Oxygen isotope data. Oxygen isotope data generated on the planktonic foraminifera Globigerinoides ruber in ML1208 cores 37BB, 31BB and 37BB (Fig. 2a) have been published elsewhere ${ }^{19}$, but here we provide additional interpretation of these data in the context of our inferences about MIS6-5. Planktonic oxygen isotope $\left(\delta^{18} \mathrm{O}\right)$ data record a combination of surface water conditions including ambient temperature, salinity and the global $\delta^{18} \mathrm{O}$ of sea water. These variables in turn reflect changes in sea-surface temperature, local precipitation, upwelling and global ice volume. Variations in $\delta^{18} \mathrm{O}$ may reflect either local processes or the signature of waters advected to our study sites, or a combination of both. Although we cannot parse the contributions of each of these variables to observed changes in the records, it is instructive to consider the relationship between $\delta^{18} \mathrm{O}$ data from the three cores and how it changes over time.

From 150 and $140 \mathrm{ka}$, oxygen isotope values for cores $37 \mathrm{BB}$ and $31 \mathrm{BB}$ are between -1.28 and $-0.8 \%$, representing substantially fresher or warmer conditions than at site 17PC $(-0.5$ to $-0.02 \%$ ). As the deglaciation begins $(\sim 140 \mathrm{ka}) \delta^{18} \mathrm{O}$ values freshen and warm at all three sites in response to rising global temperatures and reduced ice volume. However, during HS11 (136-129 ka), site 17PC shows the largest change (1.07\%), indicating that freshening and/or warming was most strongly felt at the southernmost site. At the peak of MIS5e $(\sim 120 \mathrm{ka})$, the $\delta^{18} \mathrm{O}$ recorded by foraminifera at sites $37 \mathrm{BB}, 31 \mathrm{BB}$ and $17 \mathrm{PC}$ is similar.

\section{Discussion}

Few dust flux records exist from the central equatorial Pacific, but a low-resolution record from TT013-72PC (72PC) at $0.1^{\circ} \mathrm{N}$, $139.4^{\circ} \mathrm{W}$ (ref. 20) provides an important comparison for our sediment cores. Data from 72PC show a similar decrease in dust flux from 145 to $118 \mathrm{ka}$, followed by an increase from 118 to $110 \mathrm{ka}$, in agreement with our results. Given the paucity of high-resolution marine dust flux records covering TII, the 


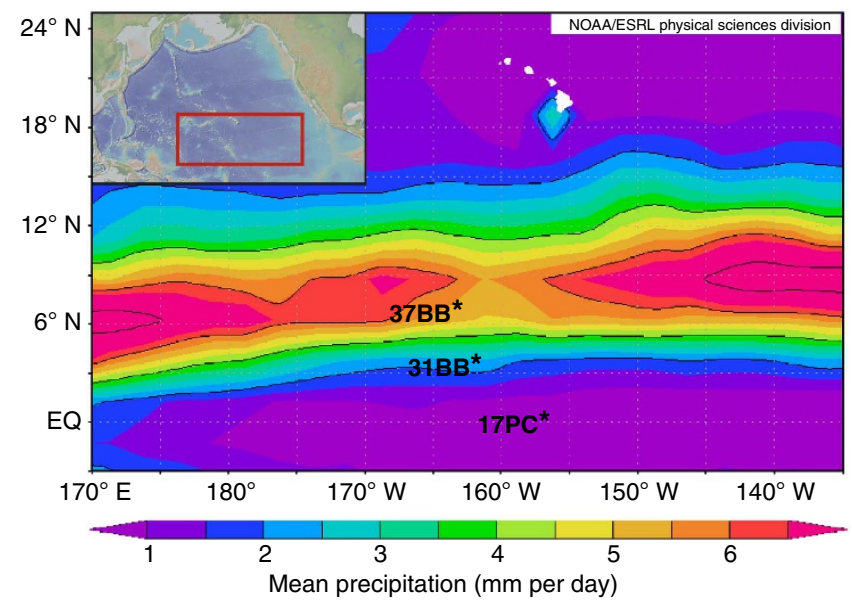

Figure 1 | Map of study area. ML1208 core sites 37BB, 31BB and 17PC (black stars) are shown relative to Hawaii (white islands), and the modern mean annual position of the ITCZ, illustrated by the maximum mean annual precipitation in $\mathrm{mm}$ per day (coloured contours). Inset shows the location of this map (red rectangle) in the broader context of the Pacific Ocean. Basemap generated using the global precipitation climatology product (GPCP) version 2.2 from National Oceanic and Atmospheric Administration's (NOAA's) Physical Sciences Division, Earth System Research Laboratory. Inset generated in GeoMapApp.

Antarctic EPICA Dome C (EDC) dust record is a valuable companion data set (Fig. 2c). Antarctic and equatorial dust fluxes co-vary at coarse resolution between hemispheres during the late Pleistocene ice-age cycles ${ }^{20}$, and in this context it is the differences between our high-resolution records and the EDC record that are the most significant. Specifically, the decline in EDC dust flux at the MIS5/6 boundary (TII at $\sim 134 \mathrm{ka}$; from $\sim 0.036$ to $0.007 \mathrm{~g} \mathrm{~m}^{-2} \mathrm{yr}^{-1}$ ) trends oppositely to the increase in dust flux observed at sites $37 \mathrm{BB}, 31 \mathrm{BB}$ and $17 \mathrm{PC}$ during HS11 (grey shading in Fig. 2). Because of the relatively high resolution of the EDC ice core and a comparable decline in dust flux in at least one other high-resolution, Southern Hemisphere record ${ }^{21}$, we hypothesize that the absence of a HS11 dust peak in the ice core record indicates that the observed dust peak in the central equatorial Pacific does not reflect an increase in global or Southern Hemisphere dust abundance, but rather an increase in northern hemisphere sources alone. Independent behaviour of Northern and Southern Hemisphere dust sources has been repeatedly observed for Heinrich stadials over the last glacial cycle ${ }^{17,22}$ (Supplementary Fig. 1c,d), and we propose that a similar hemispheric dust flux asymmetry characterized TII during HS11. Although no high-resolution dust records exist from the Northern Hemisphere covering HS11, we suggest that the increase in Northern Hemisphere dust that marked previous Heinrich stadials also characterized HS11 (ref. 23), especially since the relatively long duration of HS11 (ref. 24) would likely have allowed for the full expression of stadial conditions. Other indicators of stadial conditions ${ }^{25}$ have also identified HS11, including high ice-rafted debris (IRD) abundance in North Atlantic sediments (Fig. 2d) and cold seasurface temperatures (Fig. 2e). While not causally related to dust fluxes, these stadial indicators are repeatedly seen to change in concert with increases in Northern Hemisphere dust abundance. Recurrent intervals of high dust flux during Heinrich stadials, in combination with the clear evidence for decreased dust abundance in the Southern Hemisphere, strongly support the idea that the dust flux increases in our central equatorial Pacific cores are due to a Northern Hemisphere dust increase.
Although atmospheric dust abundance clearly varies on deglacial timescales, it cannot explain the time-variant differences in dust flux among our three sites. Instead, we attribute inter-core differences to changes in the position of the ITCZ (Fig. 3a). Our interpretations of ITCZ movement take into account our new dust flux records, planktonic oxygen isotope data from the same three sites, variations in Southern Hemisphere dust abundance as recorded in Antarctica ${ }^{17}$ and temperature proxy records that indicate the thermal gradient between poles (Fig. 2e, $\mathrm{f}$ and Supplementary Note 2).

During MIS6 ( 145 ka) dust fluxes at the three sites do not show a sufficiently clear relationship to infer confidently, on dust flux data alone, the position of the ITCZ. Instead we suggest that the similar oxygen isotope values seen at sites $37 \mathrm{BB}$ and $31 \mathrm{BB}$ indicate an ITCZ positioned approximately equidistant between the two cores. Fresher conditions at these two sites would be consistent with ITCZ-derived precipitation located directly above the sites. Colder and/or more saline conditions at 17PC are also consistent with this interpretation, as cross equatorial winds could have driven enhanced upwelling at this southernmost site as they do seasonally at present when the ITCZ is at its northernmost position ${ }^{26}$.

Between $\sim 136$ and $135 \mathrm{ka}$, coincident with the onset of HS11 in the North Atlantic (grey bar Fig. 2), dust fluxes increase in $31 \mathrm{BB}$ and 17PC, which we interpret as indicative of a southward shift in the northern edge of the ITCZ. Because dust fluxes decrease in the Southern Hemisphere from $138.5 \mathrm{ka}$ into MIS5, and because an increase in dustiness is repeatedly associated with Heinrich stadials, increasing dust fluxes in cores 31BB and 17PC indicate that they are likely receiving dust from the Northern Hemisphere. Since the ITCZ acts as a barrier to dust, the observed dust increases at $31 \mathrm{BB}$ and $17 \mathrm{PC}$ imply that the ITCZ must have been south of both of these sites. Additional evidence for an ITCZ south of $0.48^{\circ} \mathrm{N}$ during HS11 comes from contrasting the $24 \%$ increase in dust flux at the southernmost site (17PC), with the record from the intermediate core (31BB); this shows only a $9 \%$ increase, despite a higher sedimentation rate in core $31 \mathrm{BB}$ during this interval of $\sim 3.9 \mathrm{~cm} \mathrm{ka}^{-1}$ relative to a rate of $\sim 2.9 \mathrm{~cm} \mathrm{ka}^{-1}$ in core $17 \mathrm{PC}$ over the same time interval (see Methods). These increases in dust flux represent mean values for a range of data points before HS11 and during the dust flux maximum, with a maximum change in core $17 \mathrm{PC}$ of $32 \%$ and a minimum of $15 \%$, and a maximum for core $31 \mathrm{BB}$ of $21 \%$ and a minimum of $1 \%$. Here more efficient dust scavenging at 17PC suggests that the northern edge of the ITCZ was closer to that site, since at this time the source of dust to all three cores was most likely in the Northern Hemisphere. The hemispheric thermal gradient (Supplementary Note 2) supports this interpretation, as it shows rapid, deglacial Antarctic warming at a time when North Atlantic foraminifera assemblages and alkenone unsaturation indices record cold sea-surface temperatures (cf. Fig. 2e, f). This millennial-scale response of the ITCZ to changes in the hemispheric thermal gradient is consistent with models that predict ITCZ shifts in response to North Atlantic Heinrich stadials ${ }^{4}$.

Planktonic oxygen isotope data from the three sites are consistent with our inference of a southward-shifted ITCZ during the deglaciation. All three cores show a shift towards values indicating warmer, fresher conditions, but the change is largest at 17PC where a southward-shifted ITCZ may have warmed that site and/or more ITCZ precipitation may have freshened surface waters. In contrast, sites $31 \mathrm{BB}$ and $37 \mathrm{BB}$ experienced more muted freshening and warming over this time period as might be expected if the $\delta^{18} \mathrm{O}$ signal from decreasing precipitation opposed the effect of warming deglacial temperatures and decreasing ice volume. 


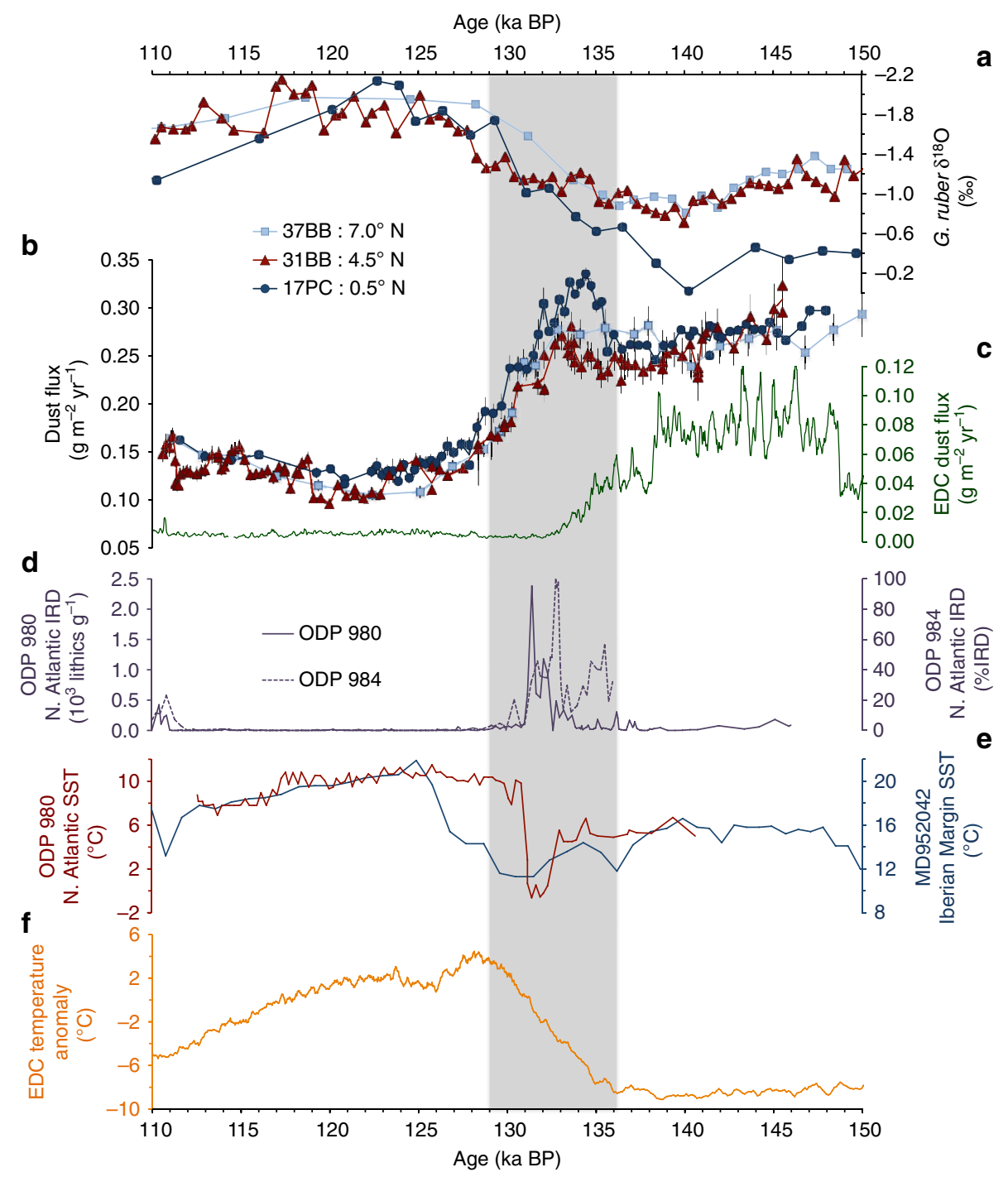

Figure 2 | Climate of the penultimate deglaciation. Planktonic foraminifera $\delta^{18} \mathrm{O}$ stratigraphy for cores $37 \mathrm{BB}$ (light blue squares), 31BB (red triangles) and $17 P C$ (navy circles) ${ }^{19}$ (a). Dust flux records from 37BB, 31BB and 17PC. Symbols as in a, error bars are 2 s.d. Lines connect data points and the mean value of replicates (b). Dust flux from Antarctic ice core EDC ${ }^{17}\left(75^{\circ} 06^{\prime} \mathrm{S}, 123^{\circ} 21^{\prime} \mathrm{E}\right.$ ) on AICC2012 chronology ${ }^{41}$ (5 pt smoothed) (c). North Atlantic (N. Atlantic) ice-rafted debris (IRD) abundance from sites ODP $980\left(55^{\circ} 29^{\prime} \mathrm{N}, 14^{\circ} 42^{\prime} \mathrm{W}\right.$ ) and ODP $984\left(61^{\circ} 25^{\prime} \mathrm{N}, 24^{\circ} 4^{\prime} \mathrm{W}\right)^{42}$ (d). North Atlantic sea surface temperature (SST) proxy records from ODP 980 (ref. 29) on the timescale of Mokeddem et al. ${ }^{42}$ (red line), and MD952042 (ref. 43 ; navy blue line) (e). Antarctic EDC temperature anomaly record ${ }^{44}$ on AICC2012 chronology ${ }^{41}$ ( 5 pt smoothed), where the anomaly is relative to the last 1,000 years (f). Grey shading represents Weak Monsoon Interval II (WMI-II) ${ }^{27}$ correlated with HS11 in the North Atlantic. Principles underlying the interpretation of proxies in e and $\mathbf{f}$ are discussed in Supplementary Note 2.

The small lag in the onset of dust flux increases in cores $31 \mathrm{BB}$ and 17PC relative to the onset of HS11 is likely an artefact of uncertainty in our age models (see Methods) and we therefore do not interpret this offset as a climate system lag. Interestingly, core $37 \mathrm{BB}$ does not appear to show an increase in dust flux coincident with the records from our other two cores. We suggest two possible reasons for this observation. First, core 37BB may be seeing relatively little dust deposition during this otherwise high-dust-abundance time period. Because it would lie significantly $\left(\sim 7^{\circ}\right)$ north of the ITCZ at this time, it is possible that dust is inefficiently scavenged from the air column above the site. Alternatively, it could be that core 37BB experienced a significant increase in dust flux during HS11, an increase that has been subsequently obscured due to relatively lower accumulation rates and the effects of bioturbation (Supplementary Note 1).
Dust levels remain above the interglacial baseline in the southernmost core until $\sim 126 \mathrm{ka}$, which could indicate that the ITCZ was in its southernmost position until that time. However, we suggest that it is more likely that the ITCZ actually began to shift northwards around $129 \mathrm{ka}$ when dust fluxes dropped below pre-stadial values, coincident with interglacial warming with stronger warming in the Northern Hemisphere. Our data display a slightly longer duration of HS11, probably due to the smoothing effects of bioturbation. This would cause HS11 to appear longer in our dust records than reconstructed from other proxies such as speleothems ${ }^{27}$, which have better age control and higher resolution but do not directly record dust fluxes or shifts in the ITCZ.

During MIS5e, all three cores record a decrease in dust flux to minimum values between 123 and $119 \mathrm{ka}$. On the basis of near-identical dust flux data for the two more northerly cores 

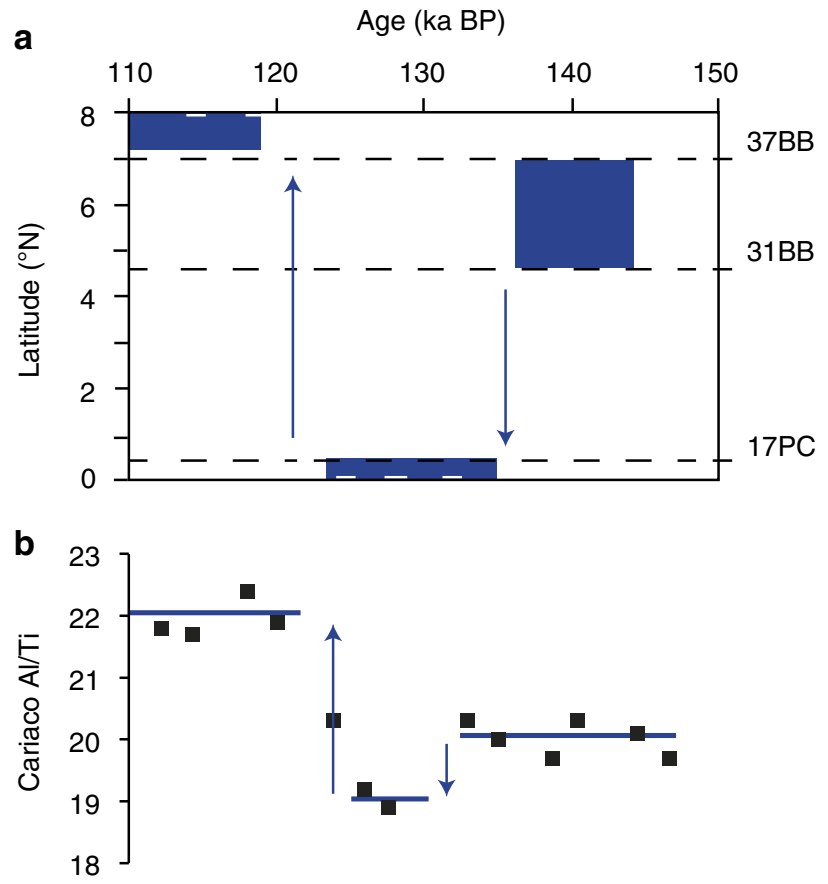

Figure 3 | Termination II ITCZ shifts. Blue boxes indicate range of possible latitudes of the mean ITCZ position, black dashed lines denote core latitudes (a). Cariaco Basin $\mathrm{Al} / \mathrm{Ti}$ record (black squares) ${ }^{28}$ with blue bars indicating estimates of the relative ITCZ position through time (b).

37BB and 31BB, we suggest that at MIS5e the ITCZ was northwards of $7^{\circ} \mathrm{N}$ and that it was not influencing any of our sites during the peak interglacial. Planktonic oxygen isotope values which are indistinguishable at the three sites during MIS5e, are consistent with this argument, as an ITCZ located north of all three cores would be unlikely to differentially influence surface hydrography or temperature at any of the three sites. It is notable that after the ITCZ retreats northward during MIS5e that the $\delta^{18} \mathrm{O}$ at site $17 \mathrm{PC}$ does not show a $0.8 \%$ enrichment relative to cores $37 \mathrm{BB}$ and $31 \mathrm{BB}$, as it did during the peak of MIS6. As suggested previously by the work on a larger set of ML1208 $\delta^{18} \mathrm{O}$ records ${ }^{19}$, this could be due to differences in the salinity of water carried by the North Equatorial Counter Current during glacial versus interglacial times. If the North Equatorial Counter Current carried fresher water from the western Pacific warm pool during MIS6 than during MIS5, a larger $\delta^{18} \mathrm{O}$ gradient would be predicted between equatorial and more northerly cores.

Our interpretation of an ITCZ located north of $7^{\circ} \mathrm{N}$ during MIS5e is consistent with a strong hemispheric thermal gradient, with the North Atlantic experiencing peak warmth at this time. At the end of MIS5e $(\sim 119 \mathrm{ka})$ interglacial temperatures subsided in both hemispheres and dust fluxes began to rise, but the differential rate of cooling appears to have been small enough that the ITCZ was not displaced southward of 37BB, since 37BB and $31 \mathrm{BB}$ show comparable dust fluxes to the end of our record at $110 \mathrm{ka}$.

Only one other record of ITCZ movement exists for the penultimate deglaciation, a record of variations in the $\mathrm{Al} / \mathrm{Ti}$ ratio from the Cariaco Basin ${ }^{28}$. The Cariaco Basin records ITCZ-driven changes in terrestrial runoff with higher (lower) ratios indicating more (less) runoff and therefore a relatively more northerly (southerly) ITCZ (Fig. 3b). Given that the Cariaco record is interpreted as recording relative movement of the terrestrial ITCZ, the agreement between our data sets is noteworthy and is consistent with the idea that ITCZ movement is likely coherent across large distances ${ }^{2}$ even on short timescales.
Model reconstructions of past ITCZ migrations have been challenging in part because of the sensitivity of the ITCZ to small changes in cloud feedbacks and energy balances ${ }^{2}$. Here we have shown that palaeo reconstructions can constrain the magnitude of even abrupt ITCZ movement, demonstrating the potential to relate ITCZ changes to the magnitude of thermal forcing and to investigate thermal and hydrological components of other climate change events. Our results provide evidence that an abrupt, millennial climate oscillation was a prominent feature of the penultimate deglaciation, both at high and low latitudes. During HS11, in concert with North Atlantic cooling ${ }^{29}$, ice rafting ${ }^{25}$, increases in northern hemisphere dust abundance, and a shift in the interhemispheric thermal gradient ${ }^{29,30}$, the ITCZ migrated southwards by at least $4^{\circ}$ relative to MIS6, and $6.5^{\circ}$ south of its present latitude. This shift likely had significant consequences for global atmospheric circulation ${ }^{10}$ and could thus have contributed to tipping the climate system over the threshold for deglaciation.

\begin{abstract}
Methods
Age model development and uncertainty. Age-depth relationships for cores ML1208-37BB, 31BB and 17PC were developed on the basis of planktonic oxygen isotope stratigraphies ${ }^{19}$ tied to the LR0 4 benthic stack ${ }^{31}$, with the assistance of a modified Monte-Carlo-enabled cross-correlation maximization scheme and random walk algorithm (MonteXCM) ${ }^{32}$. A record of coeval planktonic and benthic oxygen isotopes values was previously reconstructed in the Eastern Equatorial Pacific ${ }^{33}$, which showed zero offset between the timing of deglaciation in the two stratigraphies. This observation gives us confidence that our use of planktonic oxygen isotope stratigraphies is not introducing a significant systematic bias into the timing of our events relative to data from the ice cores.

The use of the random walk algorithm in MonteXCM allows us to quantify age uncertainty at each data point. On average, over the interval studied, 2 s.d. uncertainties are 1.5, 1.5 and $1.7 \mathrm{ka}$ for cores $37 \mathrm{BB}, 31 \mathrm{BB}$ and $17 \mathrm{PC}$, respectively. Specifically, for the HS11 interval (129-136 ka), uncertainties are $\sim 1.3,1.4$ and $1.4 \mathrm{ka}$ for the same three cores. The magnitude of these uncertainties means that it is probable that the small offsets in event timing observed between our three sediment cores are artefacts of the age model and do not represent true differences in the timing of the reconstructed dust flux changes or ITCZ shifts. However, our age constraints are sufficient to indicate that it is unlikely that these events are temporally disconnected, and a lag between the onset of HS11 and our inferred initiation of tropical changes is not inconsistent with the interpretations we present.
\end{abstract}

Dust flux reconstruction. We reconstruct dust fluxes through the quantification of ${ }^{230} \mathrm{Th}_{\mathrm{xs}, 0}$-normalized ${ }^{232} \mathrm{Th}$ fluxes in marine sediments, which act as a proxy for dust flux ${ }^{13,20}$. Terrestrial sediments contain ${ }^{232} \mathrm{Th}$ at a mean concentration of 10.7 p.p.m., which varies 1 p.p.m. or less over a range of dust provenance ${ }^{13}$. A more recent summary of ${ }^{232} \mathrm{Th}$ concentrations in dust source areas found evidence that the fine fraction $(<5 \mu \mathrm{m})$ of dust samples from a range of provenance had ${ }^{232} \mathrm{Th}$ concentrations closer to $14 \pm 1$ p.p.m. (ref. 34). We note that changing the ${ }^{232} \mathrm{Th}$ concentration used to reconstruct dust fluxes would decrease the absolute magnitude of the dust fluxes reconstructed at our study sites but does not alter our interpretations. As our core locations are a great distance from continental sources of lithogenic material, we expect ${ }^{232} \mathrm{Th}$ at our sites to be delivered predominately by aeolian processes. Indeed, grain size analyses show that the average size of lithogenic sediments at $\sim 1^{\circ} \mathrm{N} 131^{\circ} \mathrm{W}$ is $3.1 \mu \mathrm{m}$ (ref. 35), unlikely to have been derived from hemipelagic sedimentation. Here, as in other studies ${ }^{13,36}$, dust fluxes based on ${ }^{232} \mathrm{Th}$ are evaluated by normalization to ${ }^{230} \mathrm{Th}_{\mathrm{xs}, 0}$ (ref. 37).

Uranium and thorium geochemistry. Sediment samples from ML1208-37BB, $31 \mathrm{BB}$ and $17 \mathrm{PC}$ were analysed for uranium and thorium isotopes by isotope dilution and inductively coupled plasma mass spectrometry (Element XR, ICP-MS) at the Lamont-Doherty Earth Observatory of Columbia University. Between 100 and $200 \mathrm{mg}$ of sediment per sample was spiked with ${ }^{236} \mathrm{U}$ and ${ }^{229} \mathrm{Th}$ before sediment dissolution and digestion with $\mathrm{HNO}_{3}, \mathrm{HClO}_{4}$ and $\mathrm{HF}$ (ref. 38). Anion-exchange column chemistry was also used to isolate the U/Th fraction ${ }^{39}$.

Samples were run with an external in-house standard (mirroring the physical and geochemical properties of our samples) to determine measurement reproducibility, yielding relative s.d.s of $0.74 \%$ for ${ }^{238} \mathrm{U}, 1.94 \%$ for ${ }^{230} \mathrm{Th}$ and $0.87 \%$ for ${ }^{232} \mathrm{Th}$. Background contamination was evaluated in each run via blanks, which were spiked and digested, but contained no sediment. Results show ${ }^{238} \mathrm{U}$ blanks $(0.4 \mathrm{ng}),{ }^{230} \mathrm{Th}$ blanks $(0.009 \mathrm{pg})$ and ${ }^{232} \mathrm{Th}$ blanks $(1.1 \mathrm{ng})$ all of which are $<1 \%$ of even the lowest sample values. Errors reported in Fig. 2 represent 2 s.d. uncertainty estimates unique to each sample, including the propagated error due to uncertainty in counting statistics, mass bias corrections (from measurements of a natural 
${ }^{238} \mathrm{U} /{ }^{235} \mathrm{U}$ standard), counting gain corrections, spike measurements, the lithogenic fraction $(0.7 \pm 0.1)^{40}$ and a $1 \%$ age uncertainty. The average s.d. of replicate dust flux values is $\sim 6.4 \%$ of sample values. Samples for which dust flux values differed from a same-depth replicate, or an average of four nearest-neighbour data points by more than 4 s.d., have been excluded from the data set. The number of data points excluded using this method is $<5 \%$ of the total number of data points reported.

Data archiving. Line Islands dust flux data are archived at the National Oceanic and Atmospheric Administration National Centers for Environmental Information (NCEI) database and are also available as a supplement to this manuscript (Supplementary Data 1).

\section{References}

1. McGee, D., Donohoe, A., Marshall, J. H. \& Ferreira, D. Changes in ITCZ location and cross-equatorial heat transport at the Last Glacial Maximum, Heinrich Stadial 1, and the mid-Holocene. Earth Planet. Sci. Lett. 390, 69-79 (2014).

2. Schneider, T., Bischoff, T. \& Haug, G. H. Migrations and dynamics of the intertropical convergence zone. Nature 513, 45-53 (2014).

3. Donohoe, A., Marshall, J. H., Ferreira, D. \& McGee, D. The relationship between ITCZ location and cross-equatorial atmospheric heat transport: from the seasonal cycle to the last glacial maximum. J. Clim. 26, 3597-3618 (2013).

4. Chiang, J. C. H. \& Bitz, C. M. Influence of high latitude ice cover on the marine Intertropical Convergence Zone. Clim. Dynam. 25, 477-496 (2005).

5. Arbuszewski, J. A., deMenocal, P. B., Cléroux, C., Bradtmiller, L. \& Mix, A. Meridional shifts of the Atlantic intertropical convergence zone since the Last Glacial Maximum. Nat. Geosci. 6, 1-4 (2013).

6. Haug, G. H., Hughen, K. A., Sigman, D. M. \& Peterson, L. C. Southward migration of the Intertropical Convergence Zone through the Holocene. Science 293, 1304-1308 (2001).

7. Wang, X. et al. Millennial-scale precipitation changes in southern Brazil over the past 90,000 years. Geophys. Res. Lett. 34, L23701 (2007).

8. Seager, R., Kushnir, Y., Herweijer, C., Naik, N. \& Velez, J. Modeling of tropical forcing of persistent droughts and pluvials over Western North America: 1856-2000*. J. Clim. 18, 4065-4088 (2005).

9. Stager, J. C., Ryves, D. B., Chase, B. M. \& Pausata, F. S. R. Catastrophic drought in the Afro-Asian monsoon region during Heinrich Event 1. Science 331, 1299-1302 (2011)

10. Ceppi, P., Hwang, Y. T., Liu, X., Frierson, D. M. \& Hartmann, D. L. The relationship between the ITCZ and the Southern Hemispheric eddy driven jet. J. Geophys. Res. Atmos. 118, 5136-5146 (2013).

11. Lee, S.-Y., Chiang, J. C. H., Matsumoto, K. \& Tokos, K. S. Southern Ocean wind response to North Atlantic cooling and the rise in atmospheric $\mathrm{CO}_{2}$ : modeling perspective and paleoceanographic implications. Paleoceanography 26, PA1214 (2011).

12. Anderson, R. F. et al. Wind-driven upwelling in the Southern Ocean and the deglacial rise in atmospheric CO2. Science 323, 1443-1448 (2009).

13. McGee, D., Marcantonio, F. \& Lynch-Stieglitz, J. Deglacial changes in dust flux in the eastern equatorial Pacific. Earth Planet. Sci. Lett. 257, 215-230 (2007).

14. Xie, R. C. \& Marcantonio, F. Deglacial dust provenance changes in the Eastern Equatorial Pacific and implications for ITCZ movement. Earth Planet. Sci. Lett. 317-318, 386-395 (2012).

15. Pichat, S., Abouchami, W. \& Galer, S. J. G. Lead isotopes in the Eastern Equatorial Pacific record Quaternary migration of the South Westerlies. Earth Planet. Sci. Lett. 388, 293-305 (2014).

16. Husar, R. B., Prospero, J. M. \& Stowe, L. L. Characterization of tropospheric aerosols over the oceans with the NOAA advanced very high resolution radiometer optical thickness operational product. J. Geophys. Res. 102, 16889-16909 (1997).

17. Lambert, F. et al. Dust-climate couplings over the past 800,000 years from the EPICA Dome C ice core. Nature 452, 616-619 (2008).

18. Adler, R. F. et al. The Version-2 Global Precipitation Climatology Project (GPCP) monthly precipitation analysis (1979-present). J. Hydrometeorol. 4, 1147-1167 (2015).

19. Lynch-Stieglitz, J. et al. Glacial-interglacial changes in central tropical Pacific surface seawater property gradients. Paleoceanography 30, 423-438 (2015).

20. Winckler, G., Anderson, R. F., Fleisher, M. Q., McGee, D. \& Mahowald, N. Covariant glacial-interglacial dust fluxes in the Equatorial Pacific and Antarctica. Science 320, 93-96 (2008)

21. Martinez-Garcia, A. et al. Iron fertilization of the Subantarctic Ocean during the last Ice Age. Science 343, 1347-1350 (2014).

22. Ruth, U. et al. Ice core evidence for a very tight link between North Atlantic and east Asian glacial climate. Geophys. Res. Lett. 34, L03706 (2007).

23. McGee, D., Broecker, W. \& Winckler, G. Gustiness: the driver of glacial dustiness? Quatern. Sci. Rev. 29, 2340-2350 (2010).

24. Marino, G. et al. Bipolar seesaw control on last interglacial sea level. Nat. Geosci. 522, 197-201 (2015).
25. McManus, J. F., Oppo, D. W. \& Cullen, J. L. A 0.5-million-year record of millennial-scale climate variability in the North Atlantic. Science 283, 971-975 (1999).

26. Koutavas, A. \& Lynch-Stieglitz, J. Variability of the Marine ITCZ over the Eastern Pacific during the past 30,000 years: regional perspective and global context. Adv. Glob. Change Res. 21, 347-369 (2004).

27. Cheng, H. et al. Ice Age terminations. Science 326, 248-252 (2009).

28. Yarincik, K. M., Murray, R. W. \& Peterson, L. C. Climatically sensitive eolian and hemipelagic deposition in the Cariaco Basin, Venezuela, over the past 578,000 years: Results from $\mathrm{Al} / \mathrm{Ti}$ and $\mathrm{K} / \mathrm{Al}$. Paleoceanography 15, 210-228 (2000).

29. Oppo, D. W., McManus, J. F. \& Cullen, J. L. Evolution and demise of the Last Interglacial warmth in the subpolar North Atlantic. Quatern. Sci. Rev. 25, 3268-3277 (2006).

30. Parrenin, F. The EDC3 chronology for the EPICA Dome C ice core. Clim. Past 3, 485-497 (2007)

31. Lisiecki, L. E. \& Raymo, M. E. A Pliocene-Pleistocene stack of 57 globally distributed benthic $\delta^{18} \mathrm{O}$ records. Paleoceanography 20, PA1003 (2005).

32. Hoffman, J. S., Clark, P. U., Pisias, N. G., Marcott, S. A. \& Shakun, J. D. Estimating age model uncertainties for the last interglaciation. Fall Meeting, American Geophysical Union, abstract \#PP41D-1432 (2015).

33. Lea, D. W. et al. Paleoclimate history of Galápagos surface waters over the last 135,000 yr. Quatern. Sci. Rev. 25, 1152-1167 (2006).

34. McGee, D. et al. Tracking eolian dust with helium and thorium: impacts of grain size and provenance. Geochim. Cosmochim. Acta 175, 47-67 (2016).

35. Rea, D. K. \& Hovan, S. A. Grain size distribution and depositional processes of the mineral component of abyssal sediments: Lessons from the North Pacific. Paleoceanography 10, 251-258 (2010).

36. Anderson, R. F., Fleisher, M. Q. \& Lao, Y. Glacial-interglacial variability in the delivery of dust to the central equatorial Pacific Ocean. Earth Planet. Sci. Lett. 242, 406-414 (2006).

37. Francois, R., Frank, M., Rutgers van der Loeff, M. M. \& Bacon, M. P. ${ }^{230}$ Th normalization: an essential tool for interpreting sedimentary fluxes during the late Quaternary. Paleoceanography 19, PA1018 (2004).

38. Fleisher, M. Q. \& Anderson, R. F. Assessing the collection efficiency of Ross Sea sediment traps using ${ }^{230} \mathrm{Th}$ and ${ }^{231} \mathrm{~Pa}$. Deep Sea Res. II 50, 693-712 (2003).

39. Kraus, K. A., Moore, G. E. \& Nelson, F. Anion-exchange Studies. XXI. Th (IV) and U (IV) in Hydrochloric Acid. Separation of Thorium, Protactinium and Uranium1, 2. J. Am. Chem. Soc. 78, 2692-2695 (1956).

40. Bradtmiller, L. I., Anderson, R. F., Sachs, J. P. \& Fleisher, M. Q. A deeper respired carbon pool in the glacial equatorial Pacific Ocean. Earth Planet. Sci. Lett. 299, 417-425 (2010).

41. Veres, D., Bazin, L. \& Landais, A. The Antarctic ice core chronology (AICC2012): an optimized multi-parameter and multi-site dating approach for the last 120 thousand years. Clim. Past 9, 1733-1748 (2013).

42. Mokeddem, Z., McManus, J. F. \& Oppo, D. W. Oceanographic dynamics and the end of the last interglacial in the subpolar North Atlantic. Proc. Natl Acad. Sci. USA 111, 11263-11268 (2014).

43. Pailler, D. \& Bard, E. High frequency palaeoceanographic changes during the past $140000 \mathrm{yr}$ recorded by the organic matter in sediments of the Iberian Margin. Palaeogeogr. Palaeoclimatol. Palaeoecol. 181, 431-452 (2002).

44. Jouzel, J. et al. Orbital and millennial Antarctic climate variability over the past 800,000 years. Science 317, 793-796 (2007)

\section{Acknowledgements}

We thank the core repository at Lamont-Doherty Earth Observatory for providing samples, Marty Fleisher for assistance in the lab and R. Jacobel for helpful discussions. Special thanks to Jeremy Hoffman whose generous assistance with the MonteXCM algorithm improved ML1208 age models and permitted robust quantification of chronostratigraphic uncertainty. We also wish to acknowledge the contributions of Jean Lynch-Stieglitz, Pratigya Polissar, and the ML1208 science party, including the planning for and collection of the sediment cores used in this study. The manuscript was improved through the thoughtful comments of Sylvain Pichat and two anonymous reviewers. This research was funded in part by an award from the US National Science Foundation AGS-1502889 (J.F.M. and G.W.), and benefited from previous support from NSF OCE1003374, OCE-1159053, and OCE-1158886, and the Comer Science and Education Foundation.

\section{Author contributions}

A.W.J. collected all data, interpreted results and prepared the manuscript and figures; J.F.M. designed and supervised the project, and aided in interpretation and editing of the manuscript; R.F.A. and G.W. discussed interpretation of results, and contributed to the editing of the manuscript.

\section{Additional information}

Supplementary Information accompanies this paper at http://www.nature.com/ naturecommunications 
Competing financial interests: The authors declare no competing financial interests.

Reprints and permission information is available online at http://npg.nature.com/ reprintsandpermissions/

How to cite this article: Jacobel, A. W. et al. Large deglacial shifts of the pacific intertropical convergence zone. Nat. Commun. 7:10449 doi: 10.1038/ncomms10449 (2016). (c) (i) This work is licensed under a Creative Commons Attribution 4.0 International License. The images or other third party material in this article are included in the article's Creative Commons license, unless indicated otherwise in the credit line; if the material is not included under the Creative Commons license, users will need to obtain permission from the license holder to reproduce the material. To view a copy of this license, visit http://creativecommons.org/licenses/by/4.0/ 